\title{
Response Surface Modelling of Electrosprayed Polyacrylonitrile Nanoparticle Size
}

\author{
Sanaz Khademolqorani, ${ }^{1}$ Ali Zeinal Hamadani, ${ }^{2}$ and Hossein Tavanai $^{3}$ \\ ${ }^{1}$ Department of Textile Engineering, Isfahan University of Technology, Isfahan 84156-83111, Iran \\ ${ }^{2}$ Department of Industrial Engineering, Isfahan University of Technology, Isfahan 84156-83111, Iran \\ ${ }^{3}$ Department of Textile Engineering, Center of Excellence in Applied Nanotechnology, Isfahan University of Technology, \\ Isfahan 84156-83111, Iran \\ Correspondence should be addressed to Hossein Tavanai; tavanai@cc.iut.ac.ir
}

Received 9 May 2014; Accepted 29 June 2014; Published 10 August 2014

Academic Editor: Gunjan Agarwal

Copyright (C) 2014 Sanaz Khademolqorani et al. This is an open access article distributed under the Creative Commons Attribution License, which permits unrestricted use, distribution, and reproduction in any medium, provided the original work is properly cited.

\begin{abstract}
Electrospraying (electrohydrodynamic spraying) is a method of liquid atomization by electrical forces. Spraying solutions or suspensions allow production of fine particles, down to nanometer size. These particles are interesting for a wide variety of applications, thanks to their unprecedented chemical and physical behaviour in comparison to their bulk form. Knowledge of the particle size in powders is important in many studies employing nanoparticles. In this paper, the effect of some process parameters on the size of electrosprayed polyacrylonitrile particles is presented in the form of response surface model. The model is achieved by employing a factorial design to evaluate the influence of parameters on the polyacrylonitrile nanoparticle size and response surface methodology. Four electrospraying parameters, namely, applied voltage, electrospraying solution concentration, flow rate, and syringe needle diameter were considered.
\end{abstract}

\section{Introduction}

Nanoparticles are defined as particulate dispersions or solid particles with a size in the submicron range of $10-1000 \mathrm{~nm}$ [1]. Nanoparticles can be prepared from a variety of materials such as proteins, polysaccharides, and synthetic polymers. Particles in nanosize range are being investigated for a number of applications such as catalysts, cosmetics, pharmaceutics, medical, and compound materials [2-5].

The properties of materials with nanometer dimensions are significantly different from the same materials in bulk form. This is mainly due to the nanometer size of the materials leading to large fraction of surface atoms, high surface energy, spatial confinement, and reduced imperfections, which are much less pronounced in the corresponding bulk materials. Large fraction of surface atoms result in much more pronounced surface dependent properties of materials. Many of the mechanical properties of nanomaterials, including hardness, elastic modulus, and yield strength, are very different when compared with the bulk form [6-8].
With dimensions going down to nanoscale, the size of the nanomaterials is comparable to the light wavelength and the mean free path of the photons. This means that the photon transport within the materials is changed significantly because of photon confinement and quantization of photon transport, which leads to modified thermal properties [6, 9-11]. The most important property of nanoparticles, that is, inherent large surface to volume ratio, can potentially improve catalytic processes and interfacial driven phenomena such as wetting and adhesion. The estimation of the dependence of particle energy on its size is provided by the Gibbs-Thompson relation. According to this relation, lower particle size increases the chemical potential of metal atoms $[2,4,12]$. The techniques for producing the nanoparticles can be classified into "top-down" and "bottom-up" methods [3]. The top-down method transforms the material with an initial size of a few micrometers into nanoparticles with a size of only $40-200 \mathrm{~nm}$. The bottom-up method generates nanoparticles by heaping up atoms or assembling nanobuilding blocks. Electrospraying is an example of top-down 
method which is capable of producing nanoparticles. During electrospraying, under the influence of the applied electrical field, liquid flowing out from a capillary nozzle elongates and forms a cone or jet. As the voltage is increased, the jet breaks down into initial droplets. Then, the solvent evaporates from the initial droplets and the initial droplets break up to smaller particles as a result of the build-up of high repulsive forces inside them. This process which is known as Coulomb explosion continues until the final droplets reach the collector where they lose their electrical charge [13-15].

The charge and size of the droplets can be controlled to some extent by the applied voltage, electrospraying solution concentration, nozzle-collector distance, flow rate of the liquid out of the capillary nozzle, and needle diameter.

Considering the importance of the size of particles on the properties and applications of nanoparticles, in this research, the electrosprayed polyacrylonitrile nanoparticle size was modelled. To obtain the above mentioned model, at first, full factorial experimental design was chosen and nanoparticles were produced. The ANOVA analysis was used to study the significance of the treatments. Then, values for coefficients, $P$ values, and $R^{2}$ and $R_{\text {adj }}^{2}$ for response surface model were obtained by regression analysis. Response surface method is a collection of mathematical and statistical techniques, suitable for modelling and analysis of engineering applications. The response surface method is applied to situations where several input variables potentially influence some performance or characteristics of the process which are often called response. The relationship between the response ( $y$ ) and $k$ input variables could be expressed in terms of mathematical notation. Ogata et al. [16] has proposed a model for the mean volume-surface diameter of the droplets generated in the cone-jet mode of electrospraying. Tomita et al. [17] determined the frequency of droplet generation in the microdripping mode for droplet diameter less than $200 \mu \mathrm{m}$.

\section{Experimental}

2.1. Preparation of Polyacrylonitrile (PAN) Solution. To prepare PAN solution, PAN powder $\left(M_{n}=70,000 \mathrm{~g} / \mathrm{mol}\right.$, $M_{w}=100,000 \mathrm{~g} / \mathrm{mol}$ ) polymerized from acrylonitrile (94 wt.\%), methyl methacrylate (4 wt.\%), and methacrylic acid ( 2 wt.\%) (provided by Iran Polyacryl company) was dissolved in dimethylformamide (DMF, Merck) for $12 \mathrm{~h}$ at room temperature. Concentrations ranging between 1 and 3\% (w/w, weight by weight basis) were prepared.

2.2. Electrospraying of PAN Solution. The setup used for electrospraying PAN solutions, consists of a dosing pump, syringe, and needle set, aluminium foil collector, and high voltage source as shown in Figure 1. The polymer solution is placed into a syringe $(1 \mathrm{~mL})$ with the needle connected to a high voltage source and the syringe connected to dosing pump (syringe pump model STC-527, TERUMO). The horizontal syringe needle and the vertical aluminium foil collector were connected to positive and negative electrodes of high voltage source (Emersun, $220 \mathrm{~V}$, AC input-up to

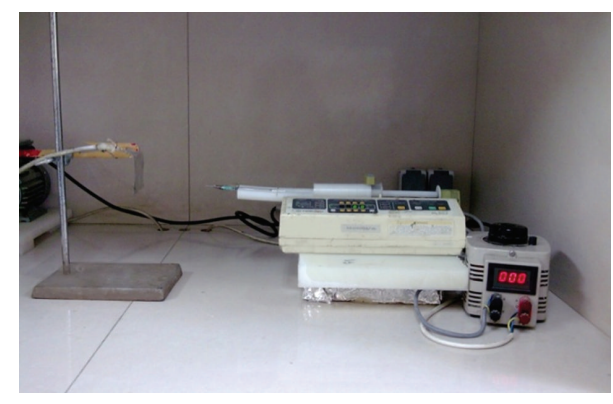

FIGURE 1: Electrospraying setup for producing PAN nanoparticles.

TABLE 1: Conditions of electrospraying PAN solution.

\begin{tabular}{lc}
\hline Factor & Factor level \\
\hline Voltage $(\mathrm{kV})$ & $10-12-14$ \\
Concentration in DMF $(\mathrm{w} / \mathrm{w} \%)$ & $1-2-3$ \\
Flow rate $(\mathrm{mL} / \mathrm{h})$ & $0.0263-0.1315$ \\
Needle diameter $(\mathrm{mm})$ & $0.6-0.8-1$ \\
\hline
\end{tabular}

$25 \mathrm{kV}$ DC output), respectively. The electrical field is formed between the collector and the tip of the syringe tube.

The levels of electrospraying variables, that is, the applied voltage, solution concentration, volume flow rate, and syringe needle diameter, are shown in Table 1 . The needle-collector distance was fixed at $15 \mathrm{~cm}$.

2.3. Measurements. After the formation of the nanoparticles on the aluminium collector, several images from each sample were taken by scanning electron microscopy (SEM, Seron Technology, AIS2100 model, Amirkabir University) and then, for all the samples, the diameter of 150 nanoparticles was measured by measurement software (manual microstructure distance measurement, Nahamin Pardazan Asia co).

\section{Modelling}

3.1. Design of Experiments. In general, design of experiments (DOE) or experimental design is the design of any information-gathering exercise where variation is present, whether under the full control of the experimenter or not. In the design of experiments, the experimenter is often interested in the effect of some process or intervention (the treatment) on one or moe outcomes of the experiment (the experimental units). It can be said that design of experiments is a discipline that has broad application in science.

A full factorial experiment is an experiment whose design consists of two or more factors, each with discrete possible values or "levels," and whose experimental units take on all possible combinations of these levels across all such factors. A full factorial design is also called a fully crossed design. Such an experiment allows studying the effect of each factor on the response variable, as well as the effects of interactions between factors on the response variable [18].

Consodering the conditions of our research, the full factorial design was chosen for data collection. Four factors 
TABLE 2: Uncoded variables for experimental and test data with corresponding responses.

\begin{tabular}{|c|c|c|c|c|c|c|}
\hline Number & $\begin{array}{c}\text { Voltage } \\
(\mathrm{kV})\end{array}$ & $\begin{array}{c}\text { Concentration } \\
(\% \mathrm{w} / \mathrm{w}) \\
\end{array}$ & $\begin{array}{c}\text { Feed rate } \\
(\mathrm{mL} / \mathrm{h})\end{array}$ & $\begin{array}{c}\text { Needle diameter } \\
(\mathrm{mm})\end{array}$ & $\begin{array}{c}\text { Mean particle size } \\
(\mathrm{nm})\end{array}$ & $\begin{array}{c}\text { Standard deviation } \\
(\mathrm{nm})\end{array}$ \\
\hline 1 & 10 & 1 & 0.263 & 1 & 190.24 & 29.76 \\
\hline 2 & 10 & 1 & 0.263 & 0.8 & 172.61 & 26.11 \\
\hline 3 & 10 & 1 & 0.263 & 0.6 & 157.89 & 24.43 \\
\hline 4 & 10 & 1 & 0.789 & 1 & 205.59 & 28.42 \\
\hline 5 & 10 & 1 & 0.789 & 0.8 & 201.63 & 30.32 \\
\hline 6 & 10 & 1 & 0.789 & 0.6 & 180.62 & 30.74 \\
\hline 7 & 10 & 1 & 1.315 & 1 & 216.66 & 31.94 \\
\hline 8 & 10 & 1 & 1.315 & 0.8 & 198.08 & 30.05 \\
\hline 9 & 10 & 1 & 1.315 & 0.6 & 185.75 & 31.77 \\
\hline 10 & 10 & 2 & 0.263 & 1 & 200.2 & 31.54 \\
\hline 11 & 10 & 2 & 0.263 & 0.8 & 184.26 & 28.14 \\
\hline 12 & 10 & 2 & 0.263 & 0.6 & 179.89 & 29.64 \\
\hline 13 & 10 & 2 & 0.789 & 1 & 227.99 & 36.64 \\
\hline 14 & 10 & 2 & 0.789 & 0.8 & 208.58 & 29.58 \\
\hline 15 & 10 & 2 & 0.789 & 0.6 & 196.21 & 28.06 \\
\hline 16 & 10 & 2 & 1.315 & 1 & 223.26 & 34.2 \\
\hline 17 & 10 & 2 & 1.315 & 0.8 & 207.55 & 31.7 \\
\hline 18 & 10 & 2 & 1.315 & 0.6 & 198.68 & 30.89 \\
\hline 19 & 10 & 3 & 0.263 & 1 & 153.72 & 19.26 \\
\hline 20 & 10 & 3 & 0.263 & 0.8 & 150.7 & 18.11 \\
\hline 21 & 10 & 3 & 0.263 & 0.6 & 142 & 24.25 \\
\hline 22 & 10 & 3 & 0.789 & 1 & 192.73 & 22.66 \\
\hline 23 & 10 & 3 & 0.789 & 0.8 & 175.5 & 25.41 \\
\hline 24 & 10 & 3 & 0.789 & 0.6 & 155.67 & 22.55 \\
\hline 25 & 10 & 3 & 1.315 & 1 & 183.05 & 24.18 \\
\hline 26 & 10 & 3 & 1.315 & 0.8 & 169.37 & 28.68 \\
\hline 27 & 10 & 3 & 1.315 & 0.6 & 162.08 & 23.35 \\
\hline 28 & 12 & 1 & 0.263 & 1 & 170.66 & 25.24 \\
\hline 29 & 12 & 1 & 0.263 & 0.8 & 165.22 & 30.33 \\
\hline 30 & 12 & 1 & 0.263 & 0.6 & 138.01 & 24.96 \\
\hline 31 & 12 & 1 & 0.789 & 1 & 202.16 & 28.4 \\
\hline 32 & 12 & 1 & 0.789 & 0.8 & 185.58 & 36.26 \\
\hline 33 & 12 & 1 & 0.789 & 0.6 & 178.41 & 30.04 \\
\hline 34 & 12 & 1 & 1.315 & 1 & 207.8 & 27.76 \\
\hline 35 & 12 & 1 & 1.315 & 0.8 & 192.2 & 34.24 \\
\hline 36 & 12 & 1 & 1.315 & 0.6 & 184.85 & 31.73 \\
\hline 37 & 12 & 2 & 0.263 & 1 & 171.72 & 26.39 \\
\hline 38 & 12 & 2 & 0.263 & 0.8 & 160.35 & 25.68 \\
\hline 39 & 12 & 2 & 0.263 & 0.6 & 156.23 & 22.78 \\
\hline 40 & 12 & 2 & 0.789 & 1 & 205.23 & 27.74 \\
\hline 41 & 12 & 2 & 0.789 & 0.8 & 190.16 & 27.68 \\
\hline 42 & 12 & 2 & 0.789 & 0.6 & 183.81 & 22.4 \\
\hline 43 & 12 & 2 & 1.315 & 1 & 222.27 & 33.65 \\
\hline 44 & 12 & 2 & 1.315 & 0.8 & 211.59 & 29.07 \\
\hline 45 & 12 & 2 & 1.315 & 0.6 & 193.61 & 31.75 \\
\hline 46 & 12 & 3 & 0.263 & 1 & 144.05 & 15.35 \\
\hline 47 & 12 & 3 & 0.263 & 0.8 & 129.18 & 16.5 \\
\hline
\end{tabular}


TABLe 2: Continued.

\begin{tabular}{|c|c|c|c|c|c|c|}
\hline Number & $\begin{array}{c}\text { Voltage } \\
(\mathrm{kV})\end{array}$ & $\begin{array}{c}\text { Concentration } \\
(\% \mathrm{w} / \mathrm{w})\end{array}$ & $\begin{array}{c}\text { Feed rate } \\
(\mathrm{mL} / \mathrm{h})\end{array}$ & $\begin{array}{l}\text { Needle diameter } \\
(\mathrm{mm})\end{array}$ & $\begin{array}{c}\text { Mean particle size } \\
(\mathrm{nm})\end{array}$ & $\begin{array}{c}\text { Standard deviation } \\
(\mathrm{nm})\end{array}$ \\
\hline 48 & 12 & 3 & 0.263 & 0.6 & 122.88 & 20.33 \\
\hline 49 & 12 & 3 & 0.789 & 1 & 163.97 & 20.19 \\
\hline 50 & 12 & 3 & 0.789 & 0.8 & 148.94 & 19.96 \\
\hline 51 & 12 & 3 & 0.789 & 0.6 & 155.36 & 21.66 \\
\hline 52 & 12 & 3 & 1.315 & 1 & 179.37 & 20.45 \\
\hline 53 & 12 & 3 & 1.315 & 0.8 & 166.75 & 25.52 \\
\hline 54 & 12 & 3 & 1.315 & 0.6 & 163.76 & 19.41 \\
\hline 55 & 14 & 1 & 0.263 & 1 & 162.35 & 20.76 \\
\hline 56 & 14 & 1 & 0.263 & 0.8 & 149.83 & 20.7 \\
\hline 57 & 14 & 1 & 0.263 & 0.6 & 140.41 & 23.51 \\
\hline 58 & 14 & 1 & 0.789 & 1 & 191.61 & 27.24 \\
\hline 59 & 14 & 1 & 0.789 & 0.8 & 177.17 & 26.99 \\
\hline 60 & 14 & 1 & 0.789 & 0.6 & 169.67 & 31.52 \\
\hline 61 & 14 & 1 & 1.315 & 1 & 195.59 & 33.24 \\
\hline 62 & 14 & 1 & 1.315 & 0.8 & 189.03 & 30.25 \\
\hline 63 & 14 & 1 & 1.315 & 0.6 & 184.73 & 29.45 \\
\hline 64 & 14 & 2 & 0.263 & 1 & 182.99 & 24.71 \\
\hline 65 & 14 & 2 & 0.263 & 0.8 & 153.93 & 25.04 \\
\hline 66 & 14 & 2 & 0.263 & 0.6 & 156.55 & 25.65 \\
\hline 67 & 14 & 2 & 0.789 & 1 & 212.26 & 26.03 \\
\hline 68 & 14 & 2 & 0.789 & 0.8 & 185.32 & 29.13 \\
\hline 69 & 14 & 2 & 0.789 & 0.6 & 172.25 & 24.09 \\
\hline 70 & 14 & 2 & 1.315 & 1 & 207.86 & 30.44 \\
\hline 71 & 14 & 2 & 1.315 & 0.8 & 194.31 & 32.21 \\
\hline 72 & 14 & 2 & 1.315 & 0.6 & 180.52 & 24.11 \\
\hline 73 & 14 & 3 & 0.263 & 1 & 146.34 & 18.94 \\
\hline 74 & 14 & 3 & 0.263 & 0.8 & 129.74 & 20.75 \\
\hline 75 & 14 & 3 & 0.263 & 0.6 & 112.78 & 19.34 \\
\hline 76 & 14 & 3 & 0.789 & 1 & 179.25 & 21.56 \\
\hline 77 & 14 & 3 & 0.789 & 0.8 & 145.38 & 21.84 \\
\hline 78 & 14 & 3 & 0.789 & 0.6 & 142.37 & 23.51 \\
\hline 79 & 14 & 3 & 1.315 & 1 & 188.52 & 25.61 \\
\hline 80 & 14 & 3 & 1.315 & 0.8 & 172.44 & 27.9 \\
\hline 81 & 14 & 3 & 1.315 & 0.6 & 159.78 & 29.9 \\
\hline
\end{tabular}

each at three levels $\left(3^{4}\right.$ design) (Table 1) resulting in 81 treatments combinations were chosen. Also, because of three levels in each parameter, quardratic modelling could be applied. Uncoded variables for experimental and test data with corresponding responses are shown in Table 2.

3.2. Response Surface Methodology (RSM). In statistics, response surface methodology (RSM) explores the relationships between several explanatory variables and one or more response variables. This method was introduced by G. E. P. Box and K. B. Wilson in 1951. The main idea of RSM is to use a sequence of designed experiments to obtain an optimal response. Box and Wilson suggest using a second-degree polynomial model to do this. They acknowledge that this model is only an approximation, but use it because such a model is easy to estimate and apply, even when little is known about the process. The planning and analysis of this study were performed within the context of RSM $[19,20]$.

\section{Results and Discussion}

In this section, a rundown on the achieved results is presented. As a typical image, Figure 2 shows the SEM image of PAN nanoparticles electrosprayed at $14 \mathrm{kV}$ voltage, $2 \mathrm{w} / \mathrm{w} \%$ solution concentration, and $0.0263 \mathrm{~mL} / \mathrm{h}$ flow rate (needle diameter $=0.8 \mathrm{~mm}$ ). The corresponding diameter 


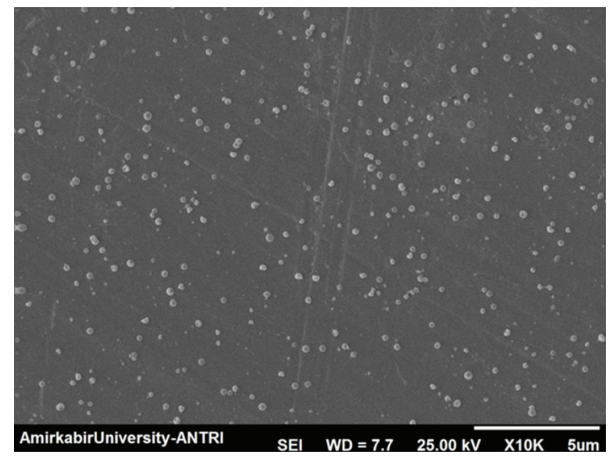

FIGURE 2: Scanning electron micrograph of polyacrylonitrile nanoparticles (voltage $=14 \mathrm{kV}$, solution conc. $=2 \mathrm{w} / \mathrm{w} \%$, flow rate $=0.0263 \mathrm{~mL} / \mathrm{h}$, and needle diameter $=0.8 \mathrm{~mm}$ ).

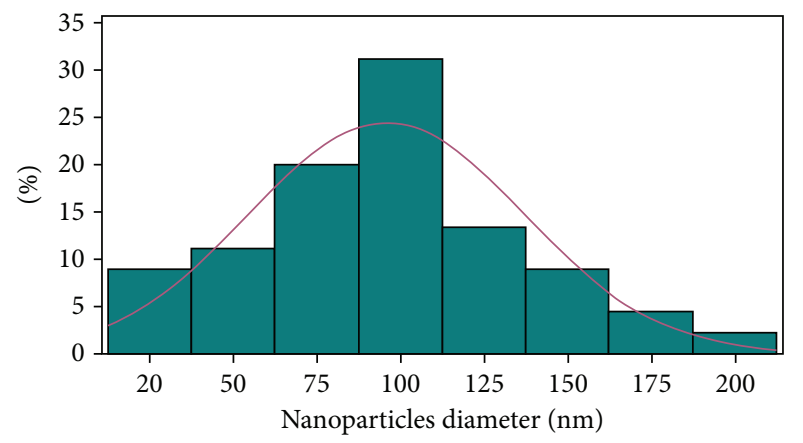

- Normal

FIgURE 3: Particle diameter disribution for PAN nanoparticles shown in Figure 2.

(size) distribution of particles shown in Figure 2 is shown in Figure 3.

In general, analysis of variance (ANOVA) is a collection of statistical models and their associated procedures in which the observed variance in a particular variable is partitioned into components attributable to different sources of variation. In its simplest form, ANOVA provides a statistical test of whether or not the means of several groups are all equal and, therefore, generalizes $t$-test to more than two groups. Doing multiple two-sample $t$-tests would result in an increased chance of committing a type I error. For this reason, ANOVA is useful in comparing three or more means. The result of the ANOVA analysis is shown in Table 3. As can be seen, all main effects and the interaction between voltage and flow rate are significant $(P$ value $<0.05)$. Regression analysis which is widely used for prediction and forecasting makes the relationship between the independent variable and the dependent variable clear. If a relationship exists, its form is explored by regression analysis. In restricted circumstances, regression analysis can be used to infer causal relationships between the independent and dependent variables. After implementing RSM to the data set, the values of coefficients and their $P$ values for regression model were obtained as presented in Table 4.
TABLE 3: ANOVA analysis.

\begin{tabular}{lccc}
\hline Source & DF & $F$ & $P$ value \\
\hline Voltage & 2 & 54.25 & $\mathbf{0 . 0 0 0}$ \\
Concentration & 2 & 237.18 & $\mathbf{0 . 0 0 0}$ \\
Feed rate $* 10$ & 2 & 231.17 & $\mathbf{0 . 0 0 0}$ \\
Needle diameter & 2 & 117.64 & $\mathbf{0 . 0 0 0}$ \\
Voltage $*$ concentration & 4 & 1.05 & 0.391 \\
Voltage $*$ feed rate & 4 & 5.81 & $\mathbf{0 . 0 0 1}$ \\
Voltage $*$ needle diameter & 4 & 1.32 & 0.278 \\
Concentration $*$ feed rate & 4 & 0.42 & 0.791 \\
Concentration $*$ needle diameter & 4 & 0.50 & 0.736 \\
Feed Rate $*$ needle diameter & 4 & 0.46 & 0.763 \\
Error & 48 & & \\
\hline Total & 80 & & \\
\hline
\end{tabular}

TABLE 4: Estimated regression coefficients.

\begin{tabular}{lcc}
\hline Term & Coefficient & $P$ value \\
\hline Constant & 309.18 & 0.000 \\
Voltage $(V)$ & -31.76 & 0.001 \\
Concentration $(C)$ & 78.18 & 0.000 \\
Flow rate $(R)$ & 45.02 & 0.003 \\
Needle diameter $(D)$ & -56.33 & 0.337 \\
$V^{2}$ & 1.04 & 0.005 \\
$C^{2}$ & -22.69 & 0.000 \\
$R^{2}$ & -32.97 & 0.000 \\
$D^{2}$ & 74.71 & 0.043 \\
$V * R$ & 3.298 & 0.001 \\
\hline
\end{tabular}

As can be seen from Table 4, the main effect of flow rate is not significant $(P$ value $>0.05)$. Furthermore, the $R^{2}$ represents the proportion of the total variability that has been explained by the regression model. The $R^{2}$ of appropriate model is about 0.96 , illustrating that the model was able to explain $96 \%$ of the variability of the mean particle size. The final response surface model fitted to the mean nanoparticle size is shown as follows:

Particle size $=309.18-31.76 V+78.18 C+45.02 R-56.33 D$

$$
\begin{aligned}
& +1.04 V^{2}-22.69 C^{2}-32.97 R^{2}+74.71 D^{2} \\
& +3.29 V R .
\end{aligned}
$$

It is worth mentioning that the practical performance of regression analysis methods depends on the form of the data generating process as well as its relationship to the employed regression approach. Since the true form of the data-generating process is in general not known, regression analysis often depends to some extent on making assumptions about this process.

These assumptions were considered for the model and are shown in Figures 4, 5, and 6. The pattern and shape of these figures confirm the validity of the model. Figure 4 shows a random pattern of residuals on both sides of zero without 


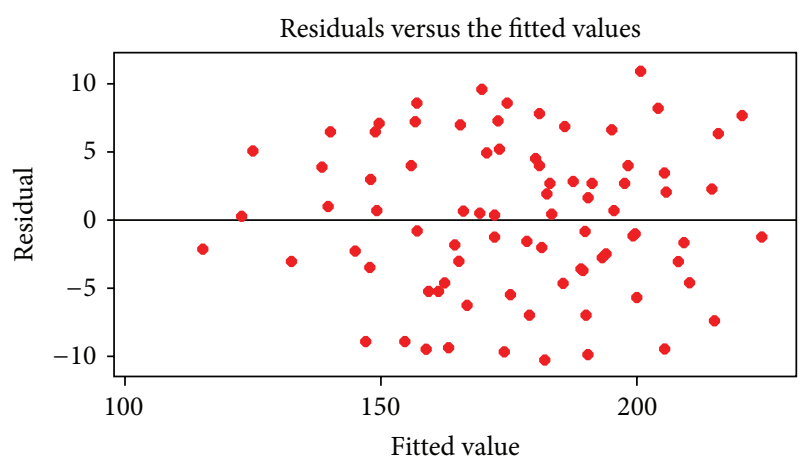

FIGURE 4: Residual versus the fitted values.

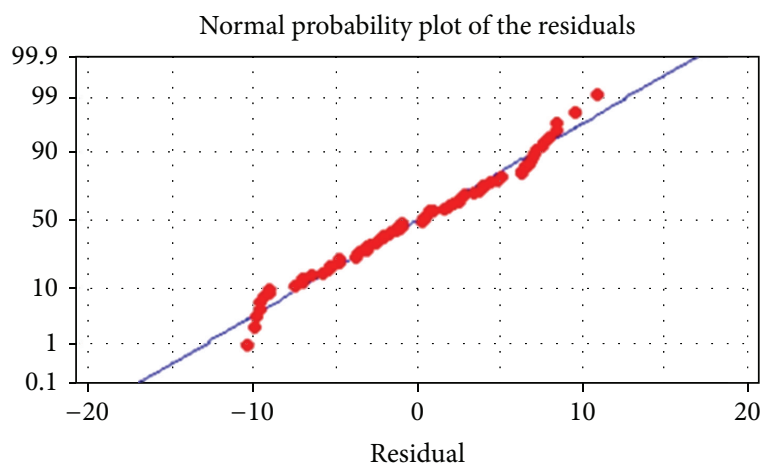

FIGURE 5: Normal probability plot of the residuals.

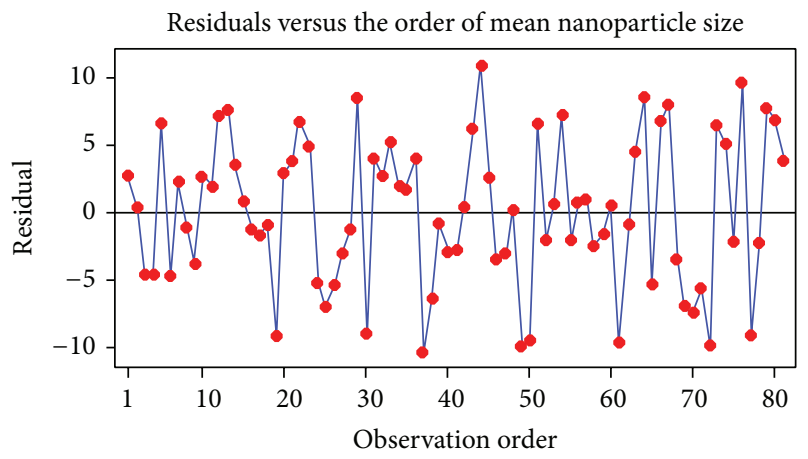

FIGURE 6: Residual versus the order of the mean nanoparticle size.

any recognizable patterns in residual plot. Figure 5 shows normal distribution, as the points in this plot should generally form a straight line. Figure 6 shows the plot of all residuals in the order that the data was collected in and can be used to find nonrandom error, especially of time-related effects. A positive correlation is indicated by the clustering of residuals with the same sign. A negative correlation is indicated by rapid changes in the signs of consecutive residuals.

After fitting RSM to data, contour plots were prepared as illustrated in Figures 7, 8, and 9. Contour plot is a graphic representation of the relationships between three numeric variables in two dimensions. Two variables represent $X$ and $Y$ axes, and a third one represents $Z$, which shows the contour levels. The contour levels are plotted as curves and the area

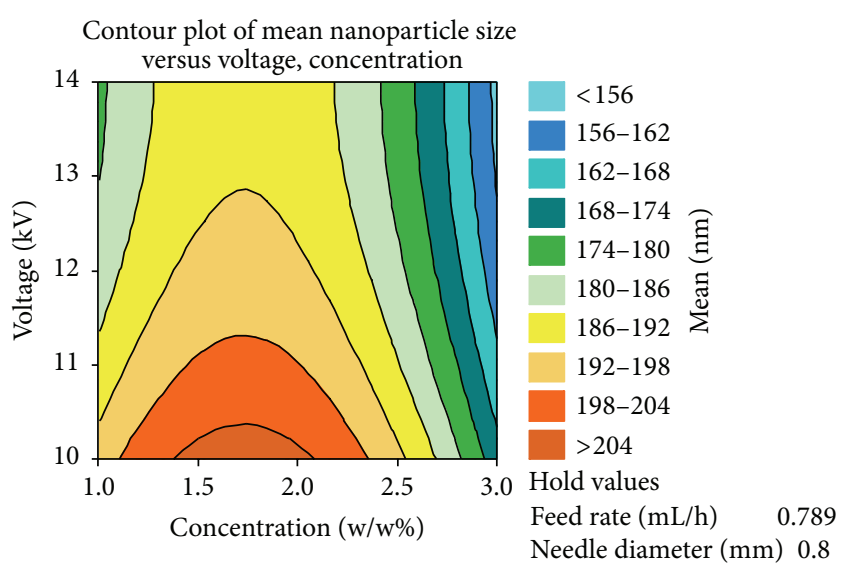

FIgURE 7: Mean nanoparticle size contour plot (Voltage versus Concentration).

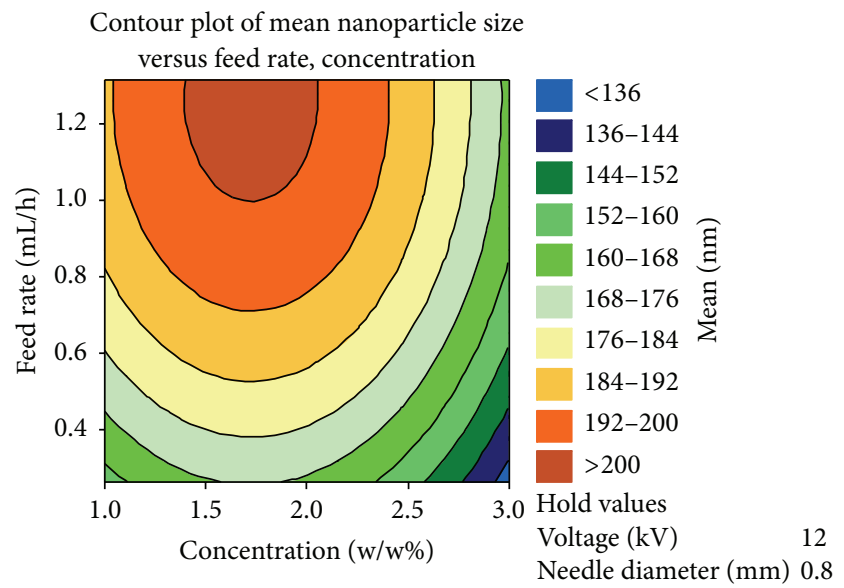

FIGURE 8: Mean nanoparticle size contour plot (Feed rate versus Concentration).

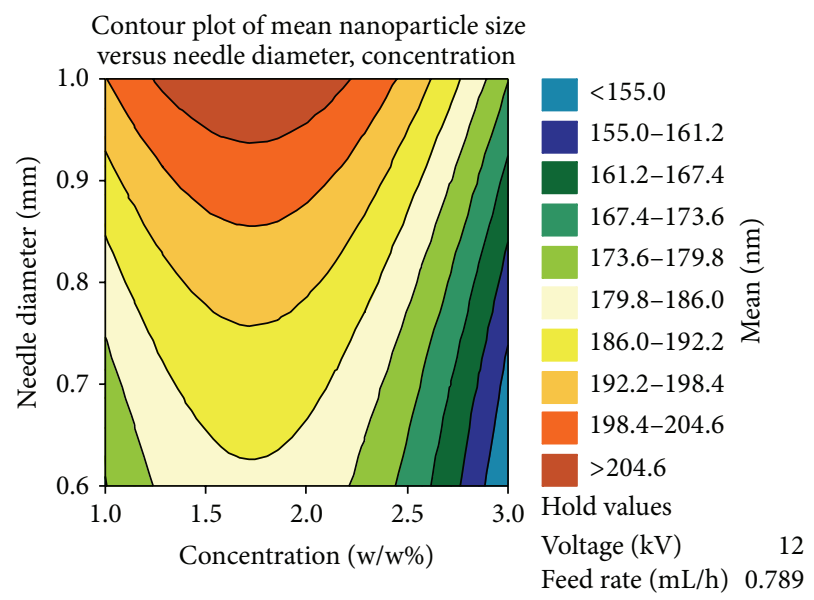

FIGURE 9: Mean nanoparticle size contour plot (Needle diameter versus Concentration).

between curves can be color coded to indicate interpolated values. For example, if a size is chosen between 156 and $162 \mathrm{~nm}$, concentration between 2.5 and $3 \mathrm{w} / \mathrm{w} \%$, voltage over 
$12 \mathrm{kV}$, needle diameter lower than $0.8 \mathrm{~mm}$, and feed rate lower than $0.8 \mathrm{~mL} / \mathrm{h}$ are recommended.

\section{Conclusion}

The effect of some process parameters on the diameter of electrosprayed polyacrylonitrile particles is presented in the form of response surface model. The validity of the model is confirmed with the help of residual versus the fitted value, normal probability plot of the residuals and residual versus the order of mean nanoparticle size.

\section{Conflict of Interests}

The authors declare that there is no conflict of interests regarding the publication of this paper.

\section{References}

[1] V. J. Mohanraj and Y. Chen, "Nanoparticles-a review," Tropical Journal of Pharmaceutical Research, vol. 5, pp. 561-573, 2006.

[2] L. Gasman, Nanotechnology Application and Markets, Artech House, London, UK, 2006.

[3] T. H. Hou, C. H. Su, and W. L. Liu, "Parameters optimization of a nano-particle wet milling process using the Taguchi method, response surface method and genetic algorithm," Powder Technology, vol. 173, no. 3, pp. 153-162, 2007.

[4] Y. Ning, "Platinum nanoparticle catalysts," Platinum Metals Review, vol. 3, no. 46, pp. 115-119, 2002.

[5] C. T. Campbell, S. C. Parker, and D. E. Starr, "The effect of size-dependent nanoparticle energetics on catalyst sintering," Science, vol. 298, no. 5594, pp. 811-814, 2002.

[6] J. T. Lue, "Physical properties of nanomaterials," in Encyclopedia of Nanoscience and Nanotechnology, vol. 5, pp. 1-46, 2007.

[7] B. Hamdoun, D. Ausserré, S. Joly, Y. Gallot, V. Cabuil, and C. Clinard, "New nanocomposite materials," Journal de Physique II, vol. 6, no. 4, pp. 493-501, 1996.

[8] D. Vollath, Nanomaterials; An Introduction to Synthesis, Properties and Application, Wiley-VCH Verlag GmbH\&Co, 2nd edition, 2013.

[9] R. Nagarajan and T. A. Hatton, Nanoparticles: Synthesis, Stabilization, Passivation and Functionalization, American Chemical Society, Washington, DC, USA, 2008.

[10] G. Schmid, Nanoparticles; from Theory to Application, WileyVCH Verlag GmbH\&Co. KGaA, 2nd edition, 2010.

[11] http://123seminarsonly.com/Seminar-Reports/016/55231535-Properties-of-Nano-Materials.pdf.

[12] E. Roduner, "Size matters: why nanomaterials are different," Chemical Society Reviews, vol. 35, no. 7, pp. 583-592, 2006.

[13] A. Jaworek and A. T. Sobczyk, "Electrospraying route to nanotechnology: an overview," Journal of Electrostatics, vol. 66, no. 3-4, pp. 197-219, 2008.

[14] K. Okuyama and W. Lenggoro, "Preparation of nanoparticles via spray route," Chemical Engineering Science, vol. 58, no. 3-6, pp. 537-547, 2003.

[15] A. Jaworek and A. Krupa, "Jet and drops formation in electrohydrodynamic spraying of liquids: a systematic approach," Experiments in Fluids, vol. 27, no. 1, pp. 43-52, 1999.

[16] S. Ogata, T. Hatae, K. Shoguchi, and H. Shinohara, "The dimensionless correlation of mean particle diameter in electrostatic atomization," International Chemical Engineering, vol. 18, no. 3, pp. $488-493,1978$.
[17] Y. Tomita, Y. Ishibashi, and T. Yooyama, "Fundamental studies on an electrostatic inkjet printer," Bulletin of the JSME, vol. 29, no. 257, pp. 3737-3743, 1986.

[18] M. Anderson, Design of Experiments, American Institute of Physics, The Industrial Physicist, 1997.

[19] D. C. Montgomery and S. M. Kowalski, Design and Analysis of Experiments, John Wiley \& Sons, New York, NY, USA, 7th edition, 2011.

[20] G. E. P. Box, J. S. Hunter, and W. Hunter, Statistics for Experimenters: Design, Innovation, and Discovery, Wiley, 2nd edition, 2005. 

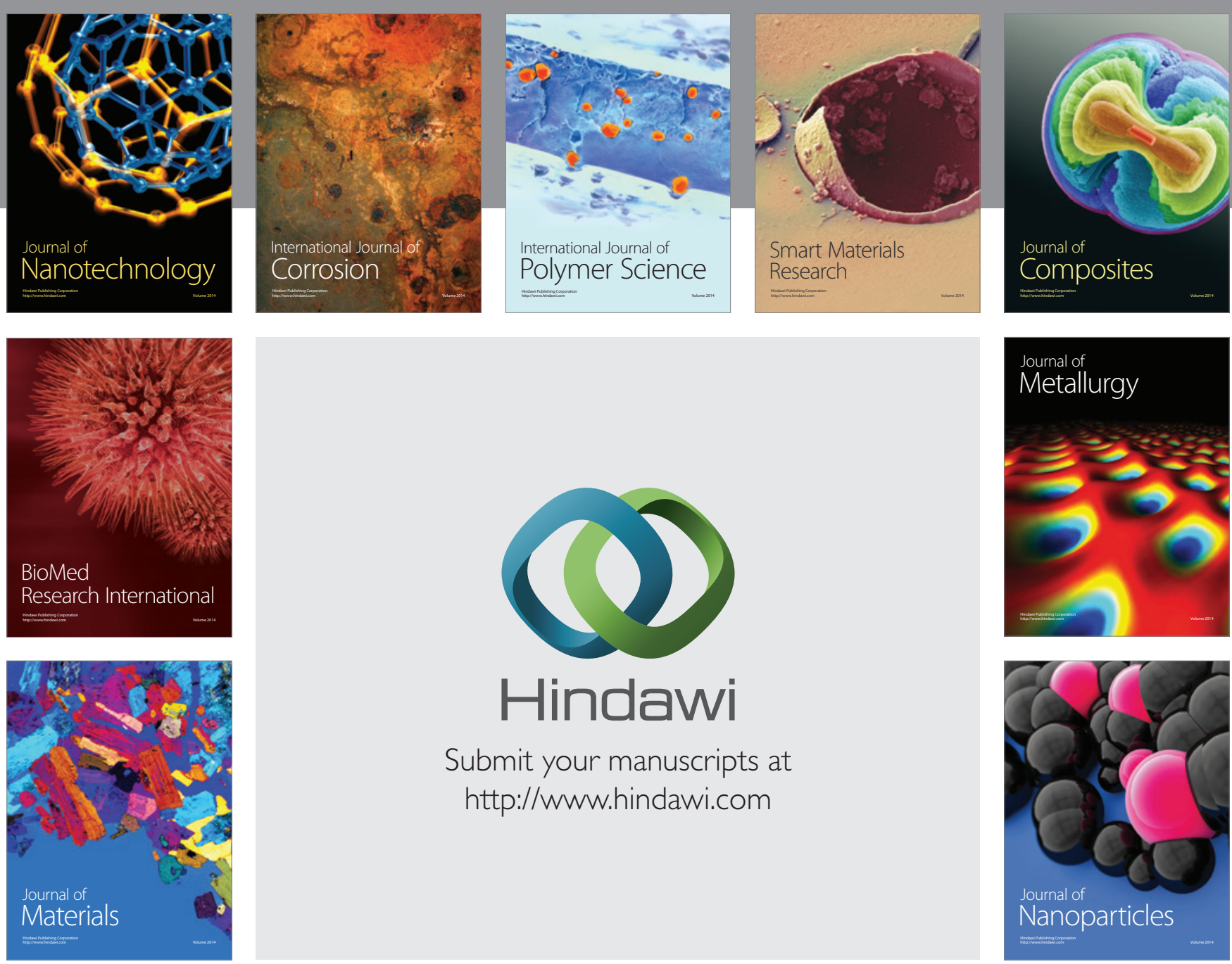

Submit your manuscripts at http://www.hindawi.com
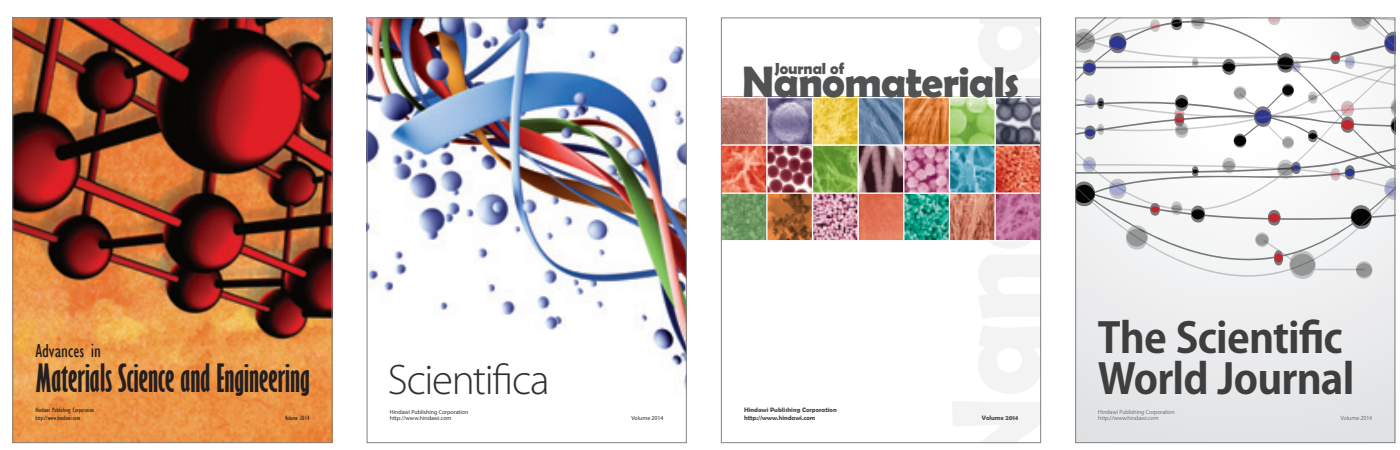

\section{The Scientific World Journal}
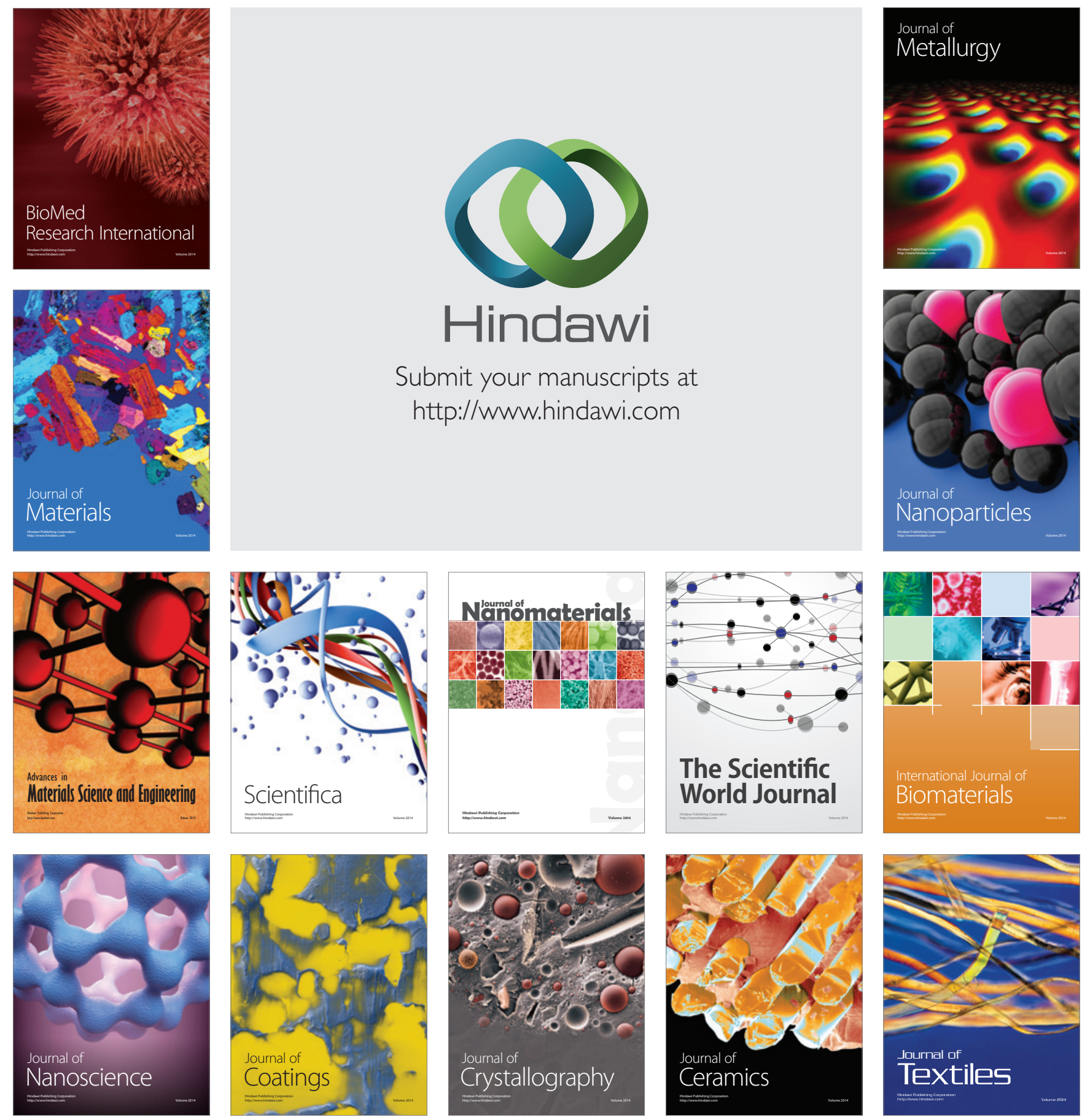